Journal of

Molecular Microbiology

and Biotechnology
J Mol Microbiol Biotechnol 2012;22:1-9

DOI: 10.1159/000336043

\title{
Periplasmic Delivery of Biologically Active Human Interleukin-10 in Escherichia coli via a Sec-Dependent Signal Peptide
}

\author{
Christoph Pöhlmann ${ }^{a} \quad$ Manuela Brandt ${ }^{a}$ Dorothea S. Mottok ${ }^{a, b}$ \\ Anke Zschüttig $^{a}$ John W. Campbell ${ }^{c}$ Frederick R. Blattner ${ }^{c, d}$ David Frisch ${ }^{c}$ \\ Florian Gunzer ${ }^{\mathrm{a}}$ \\ ${ }^{\mathrm{a}}$ Institute of Medical Microbiology and Hygiene, Dresden University of Technology, Dresden, and ${ }^{\mathrm{b}}$ Qiagen \\ Hamburg GmbH, Hamburg, Germany; ${ }^{C}$ Scarab Genomics LLC, and d Department of Genetics, University of \\ Wisconsin, Madison, Wisc., USA
}

\section{Key Words}

Escherichia coli $\cdot$ Interleukin-10 - Outer membrane protein

$\mathrm{F} \cdot$ Inflammatory bowel disease $\cdot$ Bacterial transport system vated form of the transcription factor signal transducer and activator of transcription protein 3 proved the biological activity of the bacteria-produced human IL-10.

Copyright $\odot 2012$ S. Karger AG, Basel

\begin{abstract}
Interleukin-10 (IL-10) is a potent anti-inflammatory cytokine, with therapeutic applications in inflammatory bowel disease. For the in situ delivery of IL-10 by Escherichia coli as carrier chassis, a modified transporter was designed with the ability to secrete biologically active IL-10. De novo DNA synthesis comprised a 561-bp fragment encoding the signal sequence of the $E$. coli outer membrane protein $F$ fused in frame to an E. coli codon-optimized mature human IL-10 gene under control of a T7 promoter. The construct was overexpressed in E. coli laboratory strains, E. coli BL21 (DE3) and E. coli MDS42:T7. The mean concentrations of human IL10 in the periplasm and culture supernatant of E. coli BL21 (DE3) were $355.8 \pm 86.3$ and $5.7 \pm 1.7 \mathrm{ng} / \mathrm{ml}$, respectively. The molecular mass of the recombinant $E$. coli-derived human IL-10 was $19 \mathrm{kDa}$, while under non-reducing conditions the native IL-10 dimer could be demonstrated. Reduction of tumor necrosis factor- $\alpha$ secretion in lipopolysaccharidestimulated mouse macrophages and detection of the acti-
\end{abstract}

\section{Introduction}

Gram-negative bacteria use different types of secretion systems for the transport of proteins to the periplasmic space [Pugsley, 1993]. Secretory proteins are usually synthesized as precursors with an $\mathrm{N}$-terminal signal sequence which enables export out of the cytoplasma [de Keyzer et al., 2003]. Secretory production of heterologous proteins in Escherichia coli displays several advantages compared to cytoplasmic production, such as the avoidance of inclusion body formation, correct disulfide bridging and an authentic $\mathrm{N}$-terminal amino acid sequence after signal peptide cleavage without methionine extension [Choi and Lee, 2004].

Human interleukin-10 (hIL-10) plays a major role in the regulation of inflammation and exerts its immunosuppressive properties mainly via its effect on dendritic cells and macrophages resulting in inhibition of antigen

\section{KARGER \\ Fax +41613061234 E-Mail karger@karger.ch} www.karger.com

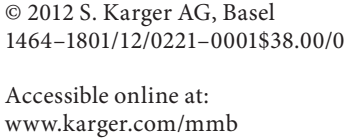

Florian Gunzer

Institute of Medical Microbiology and Hygiene

Dresden University of Technology

Fetscherstrasse 74, DE-01307 Dresden (Germany)

Tel. +49351 458 16560, E-Mail florian.gunzer@tu-dresden.de 
Fig. 1. PCR and subcloning of the ompFhIL-10 transporter construct. Amplification of a 683-bp fragment including T7 promoter, ompF signal sequence (leader) and synthetic $h I L-10$ gene from pSG1502 and insertion into pUC19 plasmid via an EcoRI restriction site leading to hIL-10 secretory vector pAZ1.

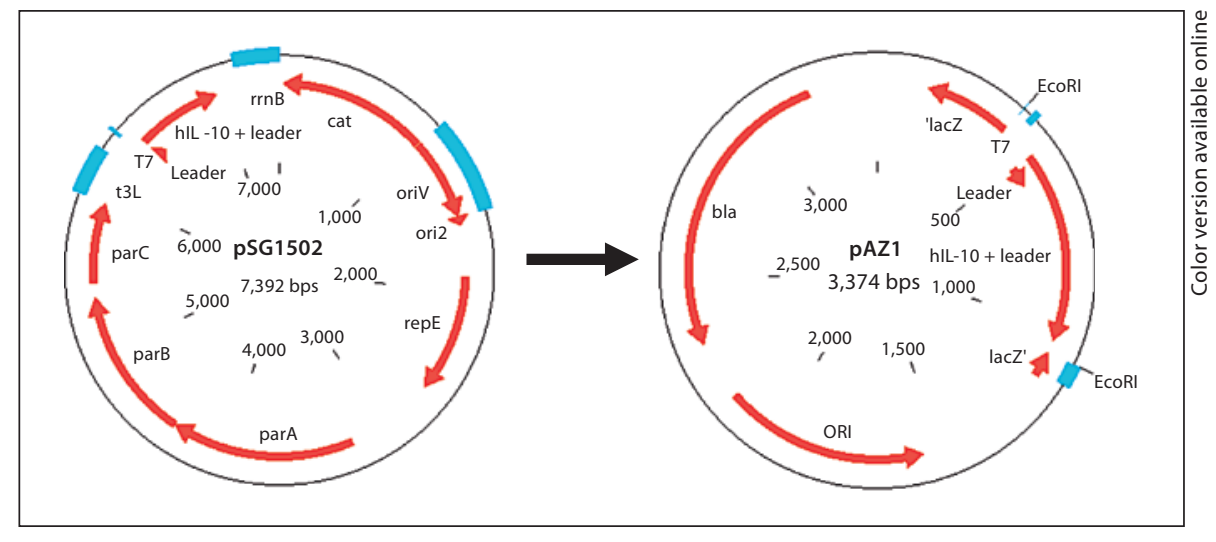

presentation, inhibition of dendritic cell differentiation and maturation, and inhibition of release of proinflammatory cytokines such as tumor necrosis factor- $\alpha$ (TNF$\alpha$ ) [Mosser and Zhang, 2008]. In experimental settings, mice genetically deficient in IL-10 have shown to succumb to severe colitis [Kühn et al., 1993], whereas systemic application of recombinant IL-10 could prevent the development of the disease [Herfarth et al., 1996]. A pilot study conducted on healthy human volunteers demonstrated suppression of proinflammatory cytokine production such as IL-1 and TNF- $\alpha$ upon IL-10 administration [Chernoff et al., 1995]. Based on these observations, hIL-10 has emerged as a promising option for the treatment of various autoimmune disorders including inflammatory bowel diseases [Mosser and Zhang, 2008]. However, administration of IL-10 by oral intake or injection of either recombinant protein or gene therapeutic vectors is limited by the acid sensitivity of the protein [Masood et al., 1995] and the induction of side effects [Fedorak et al., 2000; Schreiber et al., 2000; Tilg et al., 2002]. Therefore, an efficient delivery system specifically targeting the colon is highly desirable. Colonic IL-10 production by rectal injection of adenoviral vectors expressing IL-10 has been demonstrated [Lindsay et al., 2003], but may suffer from inconvenient delivery of the vector. Alternatively, genetically modified microorganisms provide a possible means for the in situ delivery of therapeutic proteins [Beninati et al., 2000; Krüger et al., 2002; Steidler et al., 1998]. Lactococcus lactis and Shigella flexne$r i$ strains have been engineered to secrete biologically active IL-10 [Chamekh et al., 2008; Steidler et al., 2000]. However, the good colonization properties and the lack of virulence determinants may render nonpathogenic $E$. coli strains such as probiotic E. coli Nissle 1917 a more ideal carrier chassis for intestinal drug delivery.
In this study, we constructed a modified bacterial transporter which enables T7 promoter-dependent expression and secretion of biologically active hIL-10 in laboratory E. coli strains using an E. coli codon-optimized synthetic hIL-10 gene preceded by the leader sequence of the outer membrane protein $\mathrm{F}(\mathrm{OmpF})$, a pore-forming protein of E. coli.

\section{Results and Discussion}

\section{Design and Cloning of the Artificial hIL-10 \\ Transporter}

An E. coli codon-optimized nucleotide sequence was generated from the hIL-10 gene sequence (537 bp; GenBank accession No. NM_000572). The 54-bp N-terminal eukaryotic signal sequence was replaced by the first 66 nucleotides of the ompF gene of $E$. coli K-12 MG1655 (GenBank accession No. NC_000913.2) coding for the 22 aa OmpF signal peptide. Using SignalP 3.0 software (http://www.cbs.dtu.dk/services/SignalP/, Technical University of Denmark), a high cleavage probability (score of 1.0) was predicted between aa position 22 and 23 $\left(\mathrm{ANA}^{22}-\mathrm{S}^{23} \mathrm{P}\right.$ ), delivering the mature form of the hIL-10 protein with authentic $\mathrm{N}$-terminus. Thus, a 561-bp DNA fragment was de novo synthesized in which the signal sequence of the E. coli ompF gene was fused in frame to the $5^{\prime}$ end of the mature hIL-10 synthetic gene. The DNA fragment was subsequently cloned into the BAC vector pSG1107 under the control of the T7 promoter, giving plasmid pSG1502 (fig. 1). Due to low protein expression in pSG1502-transformed E. coli BL21 (DE3) cells (data not shown), a 683-bp PCR fragment of pSG1502 including the promoter region and $o m p F-h I L-10$ construct was subcloned into pUC19 (fig. 1). The new expression vector, 
pAZ1, was isolated, sequenced, and used to transform $E$. coli BL21 (DE3) and MDS42:T7 cells.

\section{Validation of hIL-10 Expression}

In vitro production and secretion of recombinant hIL10 by the modified transporter construct was demonstrated in E. coli BL21 (DE3) and MDS42:T7 cells using a commercial sandwich ELISA. Overnight cultures were pelleted to collect the supernatant and were treated with osmotic shock to separate the periplasmic and cytoplasmic fraction. The mean hIL-10 concentrations of the culture supernatant and periplasmic fraction of E. coli BL21 (DE3) were $5.8 \pm 1.7$ and $355.8 \pm 86.3 \mathrm{ng} / \mathrm{ml}$, respectively. As negative control, supernatant and periplasmic fraction from pUC19-transformed E. coli BL21 (DE3) cells were used, and the measured OD values were below the cutoff of the assay (data not shown). Expression of recombinant hIL-10 was significantly reduced in E. coli MDS42:T7 cells with hIL-10 levels being approximately tenfold lower than in E. coli BL21 (DE3) cells (data not shown). A number of signal sequences have been employed for efficient secretory production of heterologous proteins in E. coli via the Sec-dependent secretion pathway, including pectate lyase $\mathrm{B}$ (PelB), outer membrane protein $\mathrm{A}(\mathrm{OmpA})$, alkaline phosphatase (PhoA), endoxylanase, and heat-stable enterotoxin 2 (StII) [Choi and Lee, 2004]. The $\mathrm{N}$-terminal portion of OmpF, a major outer membrane porin of $E$. coli, has also been successfully applied for secretion of foreign gene products in $E$. coli [Nagahari et al., 1985; Rockenbach et al., 1991]. By fusing the OmpF signal sequence encompassing the first 22 aa of the OmpF protein to the mature hIL-10 protein, an artificial transporter was created which allowed translocation of recombinant hIL-10 across the cytoplasmic membrane, thus showing that the modified transporter was compatible with the host secretion apparatus. The efficiency of the export was further substantiated by the fact that no recombinant hIL-10 protein could be detected in the cytoplasmic cell fraction by both ELISA and immunoblot analysis (data not shown). Interestingly, the recombinant hIL-10 protein also appeared in the culture medium in significant concentrations. Given the high hIL-10 concentration gradient across the outer cell membrane, the secretion of the recombinant protein into the culture medium was not quantitative. Whether secretion of hIL-10 into the culture medium was selective is unknown since the amount of representative periplasmic proteins such as $\beta$-lactamase or alkaline phosphatase was not assessed. The outer membrane of E. coli contains proteins such as $\mathrm{OmpF}, \mathrm{OmpC}$ and others which serve as passive diffusion pores for small hydrophilic molecules [Nikaido and Vaara, 1985]. However, the pores are likely too small for the hIL-10 molecules to be released (molecular weight of the monomer and dimer is 18.6 and 37.2 $\mathrm{kDa}$, respectively) since the pores' exclusion limit is a molecular weight of approximately $700 \mathrm{Da}$ [Nagahari et al., 1985]. Furthermore, the physicochemical properties of hIL-10 with many exposed hydrophobic residues would poorly match the pores' hydrophilic character [Zdanov et al., 1995]. Therefore, hIL-10 found in the culture medium most probably resulted from leakage from lysed bacterial cells.

\section{Processing of Signal Peptide Sequence}

One advantage of secretory protein production in $E$. coli is that, if the gene of interest is correctly fused to the cleavage site, the authentic $\mathrm{N}$-terminus without Met extension can be realized after cleavage by the signal peptidase. The C-domain of the OmpF signal peptide conforms to the $(-3,-1)$ rule [von Heijne, 1983], with the small neutral Ala residue at position -1 and -3 within the cleavage site. By replacing the hIL-10 signal sequence with the OmpF leader peptide, the original OmpF cleavage site sequence changed from $\mathrm{ANA}^{\wedge} \mathrm{AE}$ to $\mathrm{ANA}^{\wedge} \mathrm{SP}$ ( $\wedge$ indicating the beginning of the mature protein). Using the SignalP 3.0 algorithm, the cleavage site probability was predicted not to be altered significantly by modification of the processing site. Thus, processing of the $\mathrm{OmpF}$ leader peptide should result in the delivery of a recombinant hIL-10 protein with authentic $\mathrm{N}$-terminus. Immunoblots were carried out to determine the size of recombinant hIL-10 secreted into the periplasm compared to a purified mature form of the hIL-10 protein from a baculovirus expression system (R\&D Systems, Minneapolis, Minn., USA) as size marker. Figure 2a shows an immunoblot of the periplasmic fraction of both E. coli BL21 (DE3) and MDS42:T7 cells harboring the expression vector $\mathrm{pAZ1}$. In the periplasm, a hIL-10 product corresponding to the size of the commercial hIL-10 protein can be observed. However, due to the low molecular mass of the OmpF signal sequence and the poor resolution of an immunoblot gel, it cannot be precisely indicated whether or not the product of the hIL-10 fusion to the OmpF signal sequence is processed correctly during secretion in different $E$. coli strains. The absence of unprocessed material in the cytoplasm (data not shown) suggests that the fusion of hIL-10 to the OmpF signal, a product foreign to the $E$. coli cell, is fully compatible with the host secretion mechanism to allow complete secretion. 

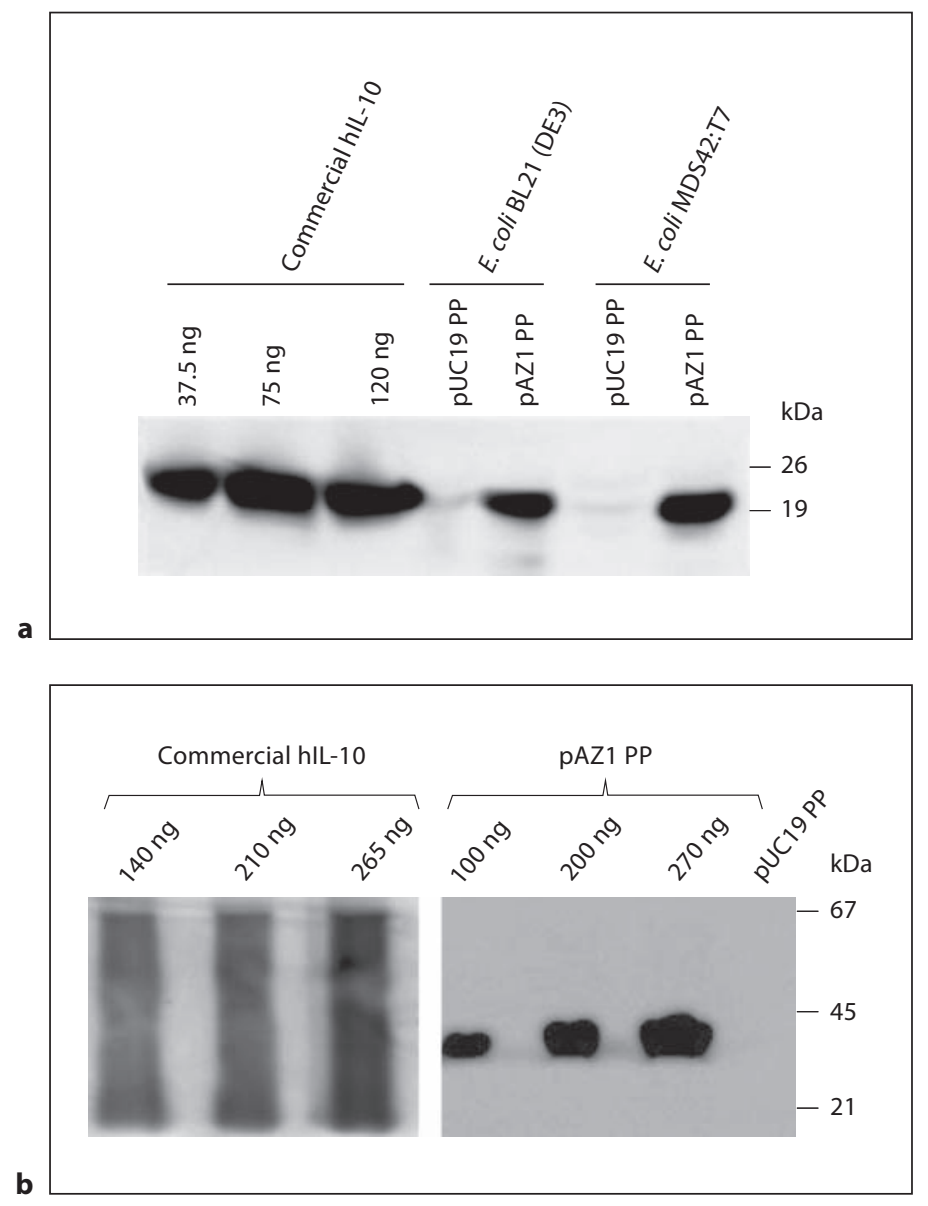

Fig. 2. a Production and secretion of recombinant hIL-10. hIL-10 (15 ng/lane) from the periplasmic fraction of pAZ1-transformed E. coli BL21 (DE3) and MDS42:T7 cells was analyzed by immunoblotting after separation by reducing SDS-PAGE. Commercial recombinant hIL-10 and the periplasmic fraction of pUC19transformed E. coli BL21 (DE3) and MDS42:T7 cells were used as controls. One experiment representative of two is shown. PP = Periplasmic fraction. b Assessment of hIL-10 dimerization. Recombinant hIL-10 from the periplasmic fraction of pAZ1-transformed E. coli BL21 (DE3) cells was analyzed by immunoblotting after separation by non-reducing BN-PAGE. Commercial recombinant hIL-10 produced in a S. frugiperda 21 (Sf 21) baculovirusderived system and the periplasmic fraction of pUC19-transformed E. coli BL21 (DE3) cells were used as controls. Different amounts of bacteria-derived and commercial hIL-10 were loaded, as indicated on top of each lane. One experiment representative of two is shown. $\mathrm{PP}=$ Periplasmic fraction.

\section{E. coli-Derived hIL-10 Is Dimeric}

The biological activity of hIL-10 strictly depends on its dimeric state [Zdanov et al., 1995]. In order to determine whether or not the E. coli-derived recombinant hIL-10 was properly assembled into dimers, the periplasmic fraction of E. coli BL21 (DE3) containing pAZ1 was concentrated and fractionated by blue native polyacrylamide gel electrophoresis (BN-PAGE) under non-reducing conditions. Immunoblot analysis confirmed that the recombinant hIL-10 was able to form dimers in the oxidative milieu of the E. coli periplasm (fig. 2b). Moreover, it appears that the dimerization of the E. coli-derived hIL-10 protein was more efficient than that of its commercially produced counterpart. The commercial hIL-10 standard which was expressed in a baculovirus infected Spodoptera frugiperda 21 cell line migrated as a smear in the BNPAGE at a molecular size range between approximately 20 and $66 \mathrm{kDa}$ (fig. $2 \mathrm{~b}$ ), indicating that the protein was at least partly existent in its monomeric form. Since the higher dimer/monomer ratio of the E. coli-derived hIL-10 was consistent regardless of the amount of protein loaded onto the gel, the possibility of an artifact caused by high protein concentration can be ruled out. The upper size limit of the hIL-10 standard's immunoblot band was at approximately $66 \mathrm{kDa}$, which might result from monomer aggregation due to protein-protein interaction. However, different amounts of the hIL-10 standard loaded onto the gel, the usage of carrier-free hIL-10 protein without BSA as stabilizer, and preincubation of the hIL-10 standard with the periplasmic fraction of pUC19-transformed E. coli BL21 (DE3) cells to rule out any influence of periplasmic proteins on the aggregation state of hIL-10 did not change the migration pattern in the BN-PAGE (data not shown). Posttranslational modification such as the linkage of carbohydrates to a potential glycosylation site at Asn residue 116 [Vieira et al., 1991] due to usage of a eukaryotic expression system might also explain the difference in the electrophoretic properties of the commercial hIL-10 standard compared to the E. coli-derived protein.

\section{Biological Activity of E. coli-Derived hIL-10}

The ability of the E. coli-derived hIL-10 to form dimers indicated that the recombinant protein was likely to retain its biological activity. We tested this hypothesis by assaying the effect of $E$. coli-derived recombinant hIL-10 on downstream components of the IL-10 signaling pathway [Moore et al., 2001] as well as by testing its inhibitory activity on the lipopolysaccharide (LPS)-induced production of TNF- $\alpha$. All anti-inflammatory effects exerted by hIL-10 require the activation of signal transducer and activator of transcription 3 (STAT3), which acts downstream of the hIL-10 receptor in human and murine cellular models [Moore et al., 2001]. We therefore studied the ability of E. coli-derived hIL-10 to phosphorylate the 


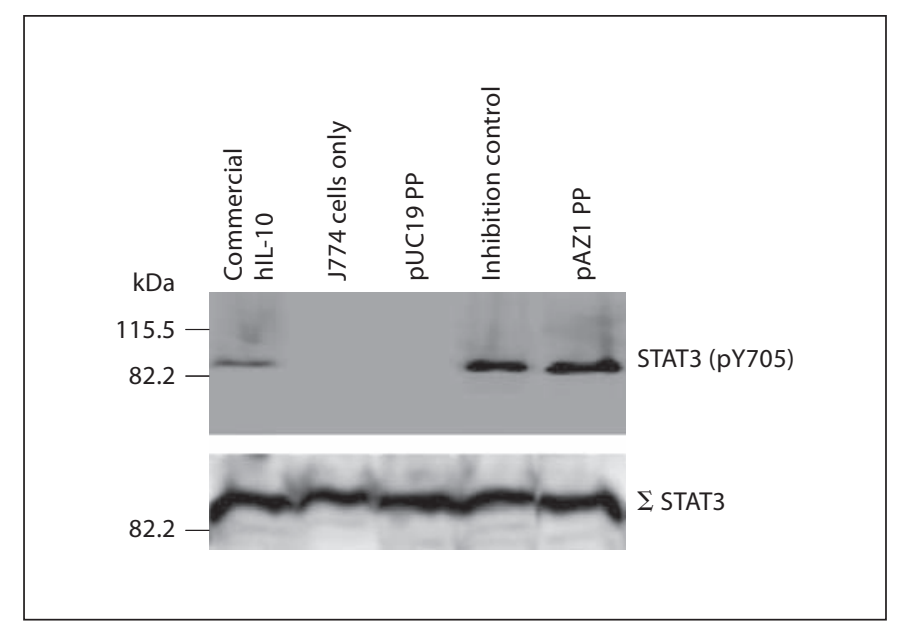

Fig. 3. Activation of STAT3 phosphorylation by E. coli-derived recombinant hIL-10. STAT3 phosphorylation (STAT3-pY705) was assessed by immunoblot analysis on protein extracts of mouse macrophage cells J774.1 treated with bacteria-derived recombinant hIL-10 at $100 \mathrm{ng} / \mathrm{ml}$. Total STAT3 was used as loading control to ensure equal amounts of protein in all lanes. The periplasmic fraction of pUC19-transformed E. coli BL21 (DE3) cells and commercial hIL-10 served as controls. Inhibition control: commercial hIL-10 at $100 \mathrm{ng} / \mathrm{ml}$ spiked with periplasm of $E$. coli BL21 (DE3) cells. One experiment representative of two is shown. PP = periplasmic fraction.

$\mathrm{Tyr}_{705}$ residue of STAT3. Stimulation of the mouse macrophage cell line J774.1 with the periplasmic fraction of pAZ1-transformed E. coli BL21 (DE3) cells containing hIL-10 in a concentration of $100 \mathrm{ng} / \mathrm{ml}$ triggered STAT3 tyrosine phosphorylation within $30 \mathrm{~min}$ of incubation time (fig. 3). At this concentration, recombinant hIL-10 was able to elicit STAT3 tyrosine phosphorylation to a degree comparable to that observed in response to commercial hIL-10 (fig. 3). No inhibitory effect due to bacterial proteins present in the periplasm was observed since STAT3 activation was equally induced by commercial hIL-10 spiked with the periplasmic fraction of E. coli BL21 (DE3) cells (fig. 3). STAT3 phosphorylation resulted specifically from the presence of recombinant hIL-10, since periplasmic fraction of pUC19-transformed E. coli BL21 (DE3) cells lacking the ability of hIL-10 expression had no detectable effect on STAT3 activation (fig. 3). These results indicate that the E. coli-derived recombinant hIL-10 protein properly interacted with its receptor and initiated the signal transduction cascade.

One of the key functions of hIL-10 is its ability to downregulate proinflammatory cytokine and chemokine expression [Ho and Moore, 1994]. Interaction of

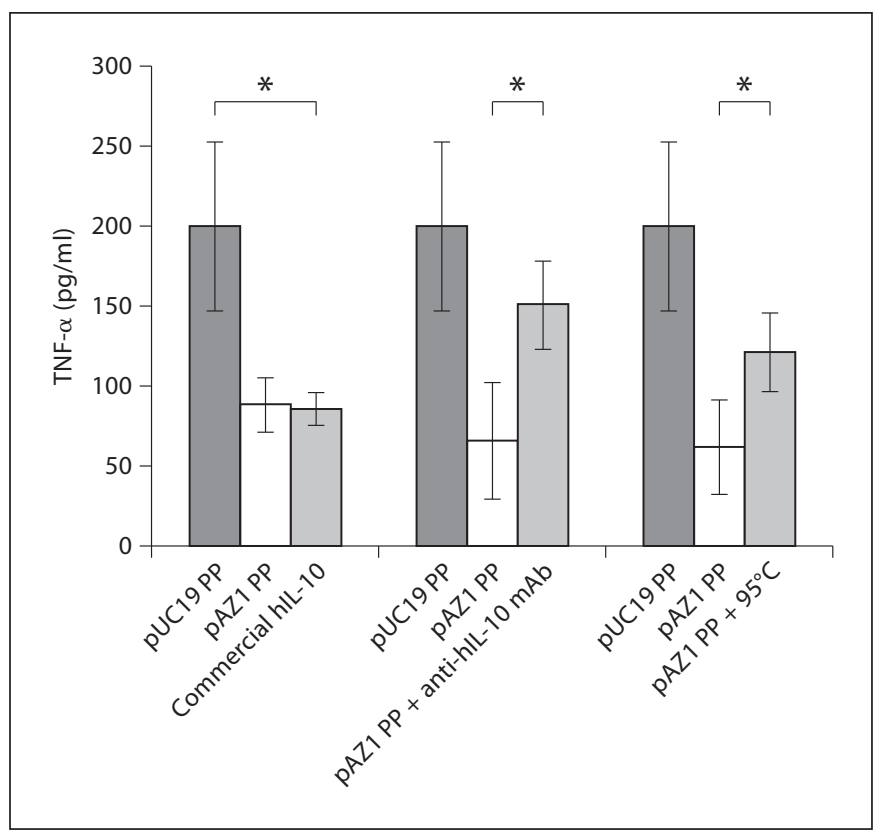

Fig. 4. Inhibition of LPS-induced TNF- $\alpha$ production by E. coliderived recombinant hIL-10. J774.1 cells were incubated with $E$. coli BL21 (DE3) pAZ1 periplasmic fraction alone (bacterial recombinant hIL-10 at $50 \mathrm{ng} / \mathrm{ml}$ ), in the presence of monoclonal anti-hIL-10 antibody, and after heat inactivation of the periplasmic fraction. Periplasmic fractions of E. coli BL21 (DE3) pUC19 were used as TNF- $\alpha$ induction control. Commercial hIL-10 (50 $\mathrm{ng} / \mathrm{ml}$ ) served as positive control. TNF- $\alpha$ secretion in the culture medium was quantified by ELISA and is reported as $\mathrm{pg} / \mathrm{ml}$ supernatant. Values are the means \pm SD of five independent experiments. Statistical significance was determined using the Student t test. Asterisk $\left(^{*}\right)$ indicates statistically significant differences ( $\mathrm{p} \leq$ 0.01) between pAZ1 PP, pUC19 PP, and pAZ1 after antihIL-10 antibody or heat treatment. PP = Periplasmic fraction; $\mathrm{mAb}=$ monoclonal antibody.

bacteria with adherent macrophages triggers the release of high amounts of the proinflammatory cytokine TNF$\alpha$ [D'Hauteville et al., 2002]. We applied this read-out system to confirm the functionality of recombinant hIL10 produced by bacteria. Stimulation of the mouse macrophage cell line J774.1 was carried out with sterile-filtered periplasm of pUC19-transformed E. coli BL21 (DE3) cells. The LPS content of the periplasmic fraction of pUC19-transformed E. coli BL21 (DE3) cells grown overnight to similar $\mathrm{A}_{600}$ values proved to be stable enough for the induction of consistent TNF- $\alpha$ levels in the culture supernatant of J774.1 cells (data not shown). Our experiments demonstrated that E. coli-derived hIL10 was able to suppress the LPS-induced production of TNF- $\alpha$ as efficiently as its commercial counterpart 
(fig. 4). The mean reduction of TNF- $\alpha$ levels was $56 \%$ for incubation of macrophages with recombinant hIL-10 containing pAZ1 periplasm compared to $57 \%$ for treatment with commercial hIL-10 (fig. 4). To determine whether the reduction of TNF- $\alpha$ production was a specific effect dependent on a functional hIL-10 protein, we performed the assay both in the presence of neutralizing anti-hIL-10 monoclonal antibodies and after heat inactivation of the pAZ1 periplasmic fraction. Neutralization of $E$. coli-derived hIL-10 by the addition of anti-hIL-10 antibodies to pAZ1 periplasm and commercial hIL-10 (data not shown) resulted in TNF- $\alpha$ levels which were comparable to those reached after macrophage induction with pUC19 periplasm (fig. 4), indicating that TNF$\alpha$ suppression was hIL-10-dependent. Heat denaturation of pAZ1 periplasmic proteins also caused a significant increase of TNF- $\alpha$ in the culture supernatant. However, TNF- $\alpha$ levels only reached $60 \%$ of those generated by pUC19 periplasm stimulation of macrophages (fig. 4). The lower TNF- $\alpha$ secretion of macrophages following incubation with heat-treated bacterial periplasm may be due to heat sensitivity of LPS cytokine-inducing activity observed at low LPS concentrations [Gao et al., 2006], which may also prevail in the periplasm. These results indicate that the E. coli secreted recombinant hIL-10 is biologically active, and that $E$. coli carrying the secretion vector pAZ1 might potentially be used as carriers for in situ delivery of therapeutics suitable to downregulate production of proinflammatory cytokines in chronic inflammatory processes such as inflammatory bowel disease. For in vivo applications in humans, it is crucial that the cytokine can be released from the periplasm in a biologically active form and that a biological containment system is provided for the genetically modified organism. Curtiss and colleagues [Kong et al., 2008] have developed a recombinant attenuated Salmonella vaccine in which regulated programmed cell lysis enables release of protective pneumococcal antigens and confers biological containment of recombinant Salmonella. In the recombinant Salmonella strain, heterologous protein expression as well as bacterial cell lysis caused by lack of essential cell wall biosynthesis enzymes are dependent on a tightly regulated arabinose operon. This system seems well suited for our construct since it also uses a Sec-dependent pathway for antigen transport into the periplasmic fraction. Periplasmic enrichment of $E$. coli-derived recombinant hIL-10 seems to be pivotal in terms of recovery of biological activity since recombinant hIL-10 from culture supernatant of pAZ1-transformed E. coli BL21 (DE3) never showed any biological activity (data not shown). Currently, we are adapting this construct to the needs of $E$. coli in order to combine secretory expression of heterologous proteins with biological containment of genetically modified host organisms.

\section{Experimental Procedures}

\section{Materials}

Restriction enzymes, proof-reading Phusion DNA polymerase and T4 DNA ligase were purchased from New England Biolabs (Beverly, Mass., USA) and were used according to the manufacturer's instructions. GoTaq DNA polymerase was from Promega (Madison, Wisc, USA). DNA sequencing kits (ABI PRISM BigDye Terminator v3.1 Cycle Sequencing Kit) were obtained from Applied Biosystems (Darmstadt, Germany). Oligonucleotide primers were synthesized by biomers.net (Ulm, Germany). Kits for plasmid mini-prep, DNA gel extraction, and PCR purification as well as DyeEx 2.0 Spin Kits for clean-up of sequencing reactions were all purchased from Qiagen (Hilden, Germany). Molecular mass markers for SDS-PAGE electrophoresis and nitrocellulose membranes for protein blotting were obtained from Invitrogen (Carlsbad, Calif., USA), native markers for BN-PAGE electrophoresis and polyvinylidene difluoride (PVDF) membranes (Immobilon-P) were from SERVA Electrophoresis (Heidelberg, Germany). A detection kit for enhanced chemiluminescence (ECL SuperSignal West Pico/Femto Substrate) was procured by Thermo Scientific (Rockford, Ill., USA). Vivaspin 20 concentrators (10,000 MWCO PES) for enrichment of recombinant hIL-10 in different cell fractions were purchased from Sartorius (Göttingen, Germany). Culture medium components were supplied from BD (Franklin Lakes, N.J., USA). The mouse macrophage cell line J774.1 was grown in complete Iscove's medium (Biochrom, Berlin, Germany) supplemented with $10 \% \mathrm{FCS}$ at $37^{\circ} \mathrm{C}$ in $5 \% \mathrm{CO}_{2} / 95 \%$ air. Other chemicals obtained from commercial sources were all of analytical grade and were used without further purification.

Bacterial Strains, Plasmids and Growth Conditions

As cloning host strain, E. coli MDS 42 [Posfai et al., 2006] was used. Protein expression analysis was carried out in E. coli BL21 (DE3) $\left[\mathrm{F}^{-}\right.$ompT $h s d S_{B}\left(\mathrm{r}_{\mathrm{b}}{ }^{-} \mathrm{m}_{\mathrm{B}}{ }^{-}\right)$gal dcm ( $\left.\left.\mathrm{\lambda DE} 3\right)\right]$ obtained from New England Biolabs and E. coli MDS42:T7. The plasmids used in this study were pUC19 (New England Biolabs) and pSG1107 (Scarab Genomics LLC, Madison, Wisc., USA). Cells were generally grown aerobically either in liquid (shaking) or on solid LuriaBertani (LB) medium ( $1 \%$ bactotryptone, $0.5 \%$ yeast extract, and $0.5 \%$ sodium chloride) [Miller, 1992] at $37^{\circ} \mathrm{C}$. Media were supplemented when appropriate with either ampicillin $(100 \mu \mathrm{g} / \mathrm{ml}$; Sigma Aldrich, St. Louis, Mo., USA) or chloramphenicol $(12.5 \mu \mathrm{g} / \mathrm{ml}$; Sigma Aldrich).

\section{DNA Sequencing}

DNA sequencing of the modified transporter construct inserted in pSG1502 and pAZ1 expression plasmids was performed by automated DNA sequencing on an ABI 3100 instrument based on dideoxy chain termination method [Sanger et al., 1977], using M13 primers for plasmid pAZ1 and pSG1502. 


\section{Transformation of E. coli Strains}

E. coli strains were made competent and transformed using standard techniques [Dower et al., 1988]. Briefly, either a 100-ng aliquot of the ligation mixture or a 20 -ng aliquot of the corresponding plasmid was added to $40 \mu \mathrm{l}$ of electrocompetent $E$. coli cells, and the mixed solution was transferred into an ice-cold 0.2 $\mathrm{cm}$ disposable cuvette (Bio-Rad Laboratories, Hercules, Calif., USA). Electroporation was conducted using a Gene Pulser Xcell electroporation system (Bio-Rad Laboratories) at $2.5 \mathrm{kV}, 25 \mu \mathrm{F}$, and $400 \Omega$ and was immediately followed by the addition of $1 \mathrm{ml}$ of SOC medium (SOB medium containing $20 \mathrm{~mm}$ glucose, $10 \mathrm{~mm}$ $\mathrm{MgSO}_{4}$, and $10 \mathrm{mM} \mathrm{MgCl}_{2}$ ). The culture was then incubated for $1 \mathrm{~h}$ at $37^{\circ} \mathrm{C} .10$ - and $100-\mu \mathrm{l}$ aliquots as well as the rest volume were spread onto LB agar containing either chloramphenicol or ampicillin and incubated for $16-18 \mathrm{~h}$ at $37^{\circ} \mathrm{C}$ to select for the antibiotic-resistant recombinants. Successful transformants were confirmed by mini-prep growth with plasmid extraction followed by restriction digestion and gel electrophoresis.

\section{Construction of the Secretion Vectors}

Molecular methods were performed as described by Sambrook et al. [1989]. To construct plasmid pSG1502, a 561-bp DNA fragment including the first 66 nucleotides of the E. coli ompF gene (NC_000913.2) encoding the signal peptide sequence fused in frame to an E. coli codon-optimized gene of the mature hIL10 (NM_000572) was de novo synthesized by Bio Basic Inc. (Markham, Ont., Canada) and subsequently cloned into NdeI/ HindIII digested pSG1107 vector resulting in plasmid pSG1502. For increased protein expression, a 683-bp fragment (including the hIL-10 gene and the T7 promoter region) was amplified from pSG1502 using Phusion DNA polymerase (New England Biolabs) and the primers SG1502T7for (GCG AAT TCC ACG ACC CTA GAG TCG AG) and SG1502h-IL10rev (GCG AAT TCC AAG GGG TTA TGC TAG TTA TC). The PCR fragment was EcoRI digested and subsequently ligated into EcoRI digested pUC19 resulting in the expression plasmid pAZ1.

\section{hIL-10 Sample Preparation}

E. coli BL21 (DE3) and MDS42:T7 cells transformed with plasmid pAZ1 were grown overnight at $37^{\circ} \mathrm{C}$ in $50 \mathrm{ml}$ of $\mathrm{LB}$ broth containing $100 \mu \mathrm{g} / \mathrm{ml}$ of ampicillin. From overnight cultures, the culture supernatant was removed and sterile filtered $(0.20 \mu \mathrm{m}$; Sarstedt, Nümbrecht, Germany). The periplasmic fraction was prepared according to the method of Neu and Heppel [1965]. Briefly, the cell pellet was resuspended in ice-cold protoplast buffer containing $30 \mathrm{~mm}$ Tris- $\mathrm{HCl}, 40 \%$ sucrose, and $2 \mathrm{~mm}$ EDTA at $1 / 10$ of the culture volume. After 15 min of incubation on ice, the cells were centrifuged at $5,000 \mathrm{~g}$ for $60 \mathrm{~min}$ at $4^{\circ} \mathrm{C}$. The supernatant fluid was discarded, and the pellet was resuspended in a volume of cold $\mathrm{ddH}_{2} \mathrm{O}$ equal to that of the original volume of the suspension. After $15 \mathrm{~min}$ of incubation on ice and centrifugation, the supernatant fluid equivalent to the periplasmic fraction was collected.

\section{Quantification of hIL-10 Expression}

Recombinant hIL-10 levels were quantified via sandwich ELISA (R\&D Systems). The assay was carried out according to the manufacturer's instructions. All samples were measured in duplicate at 450-540 nm, and cytokine levels were determined by linear regression analysis using a standard curve generated with the supplied calibration material. As negative controls, supernatant and periplasmic fraction from pUC19-transformed E. coli BL21 (DE3) and MDS42:T7 cells were used. The hIL-10 concentrations were the result of three independent experiments and presented as means $\pm \mathrm{SD}$.

\section{SDS-PAGE and BN-PAGE hIL-10 Immunoblot Analysis}

Periplasmic fractions of pAZ1-transformed E. coli BL21 (DE3) cells were separated by SDS-PAGE on a $10 \%$ (w/v) NuPAGE Novex Bis-Tris gel (Invitrogen) prior to blotting onto nitrocellulose which was blocked for $1.5 \mathrm{~h}$ with PBS supplemented with $10 \%$ (w/v) FCS and $0.1 \%$ Tween 20. Membranes were incubated overnight at $4{ }^{\circ} \mathrm{C}$ with a rabbit anti-hIL-10 antibody (PeproTech, Rocky Hills, N.J., USA) diluted at 1:5,000, followed by a second 1-hour incubation step at room temperature with a horseradish peroxidase-conjugated goat anti-rabbit immunoglobulin G (Jackson ImmunoResearch, West Grove, Pa., USA) diluted at 1:30,000. Chemoluminescence was detected by incubation with tetramethylbenzidine- $\mathrm{H}_{2} \mathrm{O}_{2}$ as substrate and subsequent analysis with a LAS 3000 (Fujifilm Europe, Düsseldorf, Germany) bioimager. Commercial hIL-10 (R\&D Systems) was used as standard.

Blue-native electrophoresis was performed using pre-cast, 1.0 mm $7 \times 8 \mathrm{~cm}$, polyacrylamide $4-16 \%$ gradient SERVA $\mathrm{N}$ gels (SERVA Electrophoresis) according to the manufacturer's instructions. Anode buffer was $50 \mathrm{~mm}$ Bis-Tris- $\mathrm{HCl}(\mathrm{pH} \mathrm{7.0)}$ and cathode buffer was $15 \mathrm{~mm}$ Bis-Tris, $50 \mathrm{~mm}$ Tricine and $0.002 \%$ (w/v) SERVA Blue G as additive ( $\mathrm{pH}$ 7.0) (SERVA Electrophoresis). Protein samples (ca. 0.1-0.3 $\mu \mathrm{g}$ hIL-10) were mixed with $2 \times$ blue native sample buffer (SERVA Electrophoresis) at a volume ratio of 3:1 and loaded onto the gel. BN-PAGE was conducted at $50 \mathrm{~V}$ for $10 \mathrm{~min}$ and thereafter at $200 \mathrm{~V}$ until the blue dye reached the bottom of the gel. Protein blotting was carried out using PVDF membranes and Towbin transfer buffer ( $0.025 \mathrm{M}$ Tris, $0.192 \mathrm{M}$ glycine) containing $20 \%(\mathrm{v} / \mathrm{v})$ methanol. Protein detection was performed as described for SDS-PAGE immunoblot analysis.

SDS-PAGE and BN-PAGE immunoblot data were the result of at least two independent experiments.

\section{In vitro Assays for Characterization of hIL-10 Biological} Activity

(a) TNF- $\alpha$ Cell Assay. Prior to the experiment, J774.1 cells were seeded at a density of $1 \times 10^{5} / \mathrm{ml}$ in 24 -well tissue culture plates and were then incubated for $2 \mathrm{~h}$ at $37^{\circ} \mathrm{C}$. Recombinant hIL-10 from the periplasmic fraction of pAZ1-transformed E. coli BL21 (DE3) cells was either preincubated alone at $37^{\circ} \mathrm{C}$, in the presence of neutralizing anti-IL-10 monoclonal antibody (R\&D Systems) or denatured at $95^{\circ} \mathrm{C}$ for $30 \mathrm{~min}$, filled up to equal volumes with LPS containing periplasmic fraction of pUC19-transformed $E$. coli BL21 (DE3) cells, and then added to J774.1 cells at a concentration of $50 \mathrm{ng} / \mathrm{ml}$. After $4 \mathrm{~h}$ of incubation at $37^{\circ} \mathrm{C}$, the amount of TNF- $\alpha$ released in the medium was measured in duplicate by ELISA (R\&D Systems) according to the manufacturer's instructions. Periplasmic fraction of pUC19-transformed E. coli BL21 (DE3) was used as TNF- $\alpha$ induction control. Commercial hIL-10 (R\&D Systems) served as positive control. Presented values were the result of five independent experiments.

(b) STAT3 Cell Assay. J774.1 cells were incubated for $30 \mathrm{~min}$ at $5 \times 10^{6}$ per well with recombinant hIL-10 from the periplasmic fraction of pAZ1-transformed E. coli BL21 (DE3) cells, then harvested and treated with cell lysis buffer (RIPA buffer; Sigma Al- 
drich) containing inhibitors of proteases (Complete Mini; Roche Applied Science, Mannheim, Germany) and phosphatases (Phosphostop; Roche Applied Science) for $1 \mathrm{~h}$ at $4^{\circ} \mathrm{C}$. Cell lysates were clarified by centrifugation, and the supernatants were then analyzed by SDS-PAGE on a 10\% (w/v) NuPAGE Novex Bis-Tris gel (Invitrogen) and subsequent immunoblotting with polyclonal antibodies directed against either phospho-STAT3 (Y705) (Cell Signaling Technology, Danvers, Mass., USA) or total STAT3 (C-20) (Santa Cruz Biotechnology, Santa Cruz, Calif., USA), both diluted at 1:1,000. Horseradish peroxidase-conjugated goat anti-rabbit immunoglobulin $\mathrm{G}$ (Jackson ImmunoResearch) diluted at 1: 25,000 was utilized for detection. The periplasmic fraction of pUC19-transformed E. coli BL21 (DE3) and commercial hIL-10 (R\&D Systems) were used as controls. STAT3 immunoblot data were the result of at least two independent experiments.
Statistical Analysis

All data presented as means \pm SD. Student's t test was used to determine the statistical significance. $\mathrm{p}<0.05$ was considered statistically significant.

\section{Acknowledgments}

This work was funded by a grant of the 'MeDDrive38' program of the TU Dresden, Medical Faculty, Carl Gustav Carus to C.P. and by a grant of the Federal Ministry of Education and Research (BMBF GenomikTransfer, PROTumor consortium) to F.G. We would also like to acknowledge Michael Hogardt (Max von Pettenkofer Institute, Munich, Germany) for providing the mouse macrophage cell line J774.1.

\section{References}

Beninati C, Oggioni MR, Boccanera M, Spinosa MR, Maggi T, Conti S, Magliani W, De Bernardis F, Teti G, Cassone A, Pozzi G, Polonelli L: Therapy of mucosal candidiasis by expression of an anti-idiotype in human commensal bacteria. Nat Biotechnol 2000;18: 1060-1064.

Chamekh M, Phalipon A, Quertainmont R, Salmon I, Sansonetti P, Allaoui A: Delivery of biologically active anti-inflammatory cytokines IL-10 and IL-1ra in vivo by the Shigella type III secretion apparatus. J Immunol 2008; 180:4292-4298.

Chernoff AE, Granowitz EV, Shapiro L, Vannier E, Lonnemann G, Angel JB, Kennedy JS, Rabson AR, Wolff SM, Dinarello CA: A randomized, controlled trial of IL-10 in humans. Inhibition of inflammatory cytokine production and immune responses. J Immunol 1995;154:5492-5499.

Choi JH, Lee SY: Secretory and extracellular production of recombinant proteins using Escherichia coli. Appl Microbiol Biotechnol 2004; 64:625-635.

de Keyzer J, van der Does C, Driessen AJ: The bacterial translocase: a dynamic protein channel complex. Cell Mol Life Sci 2003;60: 2034-2052.

D’Hauteville H, Khan S, Maskell DJ, Kussak A, Weintraub A, Mathison J, Ulevitch RJ, Wuscher N, Parsot C, Sansonetti PJ: Two $\mathrm{msbB}$ genes encoding maximal acylation of lipid A are required for invasive Shigella flexneri to mediate inflammatory rupture and destruction of the intestinal epithelium. J Immunol 2002;168:5240-5251.

Dower WJ, Miller JF, Ragsdale CW: High efficiency transformation of $E$. coli by high-voltage electroporation. Nucleic Acids Res 1988; 16:6127-6145.
Fedorak RN, Gangl A, Elson CO, Rutgeerts P, Schreiber S, Wild G, Hanauer SB, Kilian A, Cohard M, LeBeaut A, Feagan B: Recombinant human interleukin-10 in the treatment of patients with mild to moderately active Crohn's disease. The Interleukin-10 Inflammatory Bowel Disease Cooperative Study Group. Gastroenterology 2000;119:14731482 .

Gao B, Wang Y, Tsan MF: The heat sensitivity of cytokine-inducing effect of lipopolysaccharide. J Leukoc Biol 2006;80:359-366.

Herfarth HH, Mohanty SP, Rath HC, Tonkonogy S, Sartor RB: Interleukin-10 suppresses experimental chronic, granulomatous inflammation induced by bacterial cell wall polymers. Gut 1996;39:836-845.

Ho AS, Moore KW: Interleukin-10 and its receptor. Ther Immunol 1994;1:173-185.

Kong W, Wanda SY, Zhang X, Bollen W, Tinge SA, Roland KL, Curtiss R 3rd: Regulated programmed lysis of recombinant Salmonella in host tissues to release protective antigens and confer biological containment. Proc Natl Acad Sci USA 2008; 105:93619366.

Krüger C, Hu Y, Pan Q, Marcotte H, Hultberg A, Delwar D, van Dalen PJ, Pouwels PH, Leer RJ, Kelly CG, van Dollenweerd C, Ma JK, Hammarström L: In situ delivery of passive immunity by lactobacilli producing singlechain antibodies. Nat Biotechnol 2002;20: 702-706.

Kühn R, Löhler J, Rennick D, Rajewsky K, Müller W: Interleukin-10-deficient mice develop chronic enterocolitis. Cell 1993;75:263-274.

Lindsay JO, Ciesielski CJ, Scheinin T, Brennan FM, Hodgson HJ: Local delivery of adenoviral vectors encoding murine interleukin-10 induces colonic interleukin-10 production and is therapeutic for murine colitis. Gut 2003;52:981-987.
Masood R, Zhang Y, Bond MW, Scadden DT, Moudgil T, Law RE, Kaplan MH, Jung B, Espina BM, Lunardi-Iskandar Y, et al.: Interleukin-10 is an autocrine growth factor for acquired immunodeficiency syndrome-related B-cell lymphoma. Blood 1995;85:34233430.

Miller JH: A Short Course in Bacterial Genetics: A Laboratory Manual and Handbook for Escherichia coli and Related Bacteria. Cold Spring Harbor, Cold Spring Harbor Laboratory Press, 1992.

Moore KW, de Waal Malefyt R, Coffman RL, O'Garra A: Interleukin-10 and the interleukin-10 receptor. Annu Rev Immunol 2001; 19:683-765.

Mosser DM, Zhang X: Interleukin-10: new perspectives on an old cytokine. Immunol Rev 2008;226:205-218.

Nagahari K, Kanaya S, Munakata K, Aoyagi Y, Mizushima S: Secretion into the culture medium of a foreign gene product from Escherichia coli: use of the ompF gene for secretion of human $\beta$-endorphin. EMBO J 1985;4: 3589-3592.

Neu HC, Heppel LA: The release of enzymes from Escherichia coli by osmotic shock and during the formation of spheroplasts. J Biol Chem 1965;240:3685-3692.

Nikaido H, Vaara M: Molecular basis of bacterial outer membrane permeability. Microbiol Rev 1985;49:1-32.

Posfai G, Plunkett G, 3rd, Feher T, Frisch D, Keil GM, Umenhoffer K, Kolisnychenko V, Stahl B, Sharma SS, de Arruda M, Burland V, Harcum SW, Blattner FR: Emergent properties of reduced-genome Escherichia coli. Science 2006;312:1044-1046.

Pugsley AP: The complete general secretory pathway in Gram-negative bacteria. Microbiol Rev 1993;57:50-108. 
Rockenbach SK, Dupuis MJ, Pitts TW, Marschke CK, Tomich CS: Secretion of active truncated CD4 into Escherichia coli periplasm. Appl Microbiol Biotechnol 1991;35:32-37.

Sambrook J, Fritsch EF, Maniatis T: Molecular Cloning: A Laboratory Manual, ed 2. Cold Spring Harbor, Cold Spring Harbor Laboratory Press, 1989.

Sanger F, Nicklen S, Coulson AR: DNA sequencing with chain-terminating inhibitors. Proc Natl Acad Sci USA 1977;74:5463-5467.

Schreiber S, Fedorak RN, Nielsen OH, Wild G, Williams CN, Nikolaus S, Jacyna M, Lashner BA, Gangl A, Rutgeerts P, Isaacs K, van Deventer SJ, Koningsberger JC, Cohard M, LeBeaut A, Hanauer SB: Safety and efficacy of recombinant human interleukin-10 in chronic active Crohn's disease. Crohn's Disease IL-10 Cooperative Study Group. Gastroenterology 2000;119:1461-1472.
Steidler L, Hans W, Schotte L, Neirynck S, Obermeier F, Falk W, Fiers W, Remaut E: Treatment of murine colitis by Lactococcus lactis secreting interleukin-10. Science 2000;289: 1352-1355.

Steidler L, Robinson K, Chamberlain L, Schofield KM, Remaut E, Le Page RW, Wells JM: Mucosal delivery of murine interleukin-2 (IL-2) and IL-6 by recombinant strains of Lactococcus lactis coexpressing antigen and cytokine. Infect Immun 1998;66:3183-3189.

Tilg H, Ulmer H, Kaser A, Weiss G: Role of IL-10 for induction of anemia during inflammation. J Immunol 2002;169:2204-2209.
Vieira P, de Waal-Malefyt R, Dang MN, Johnson KE, Kastelein R, Fiorentino DF, deVries JE, Roncarolo MG, Mosmann TR, Moore KW: Isolation and expression of human cytokine synthesis inhibitory factor cDNA clones: homology to Epstein-Barr virus open reading frame BCRFI. Proc Natl Acad Sci USA 1991; 88:1172-1176.

von Heijne G: Patterns of amino acids near signal-sequence cleavage sites. Eur J Biochem 1983;133:17-21.

Zdanov A, Schalk-Hihi C, Gustchina A, Tsang M, Weatherbee J, Wlodawer A: Crystal structure of interleukin-10 reveals the functional dimer with an unexpected topological similarity to interferon- $\gamma$. Structure 1995;3: 591-601. 